\title{
Chemical Determination of Iodinated Compounds in Human Thyroid
}

\author{
Toshiro NAKASHIMA*, Akiyo SHIROOZU, Ken OKAMURA, \\ Kenjiro INOUE** and TERUo OMAE
}

\author{
Second Department of Internal Medicine, Faculty of Medicine \\ Kyushu University, Fukuoka 812, Japan
}

\begin{abstract}
Synopsis
As a tool with which to detect iodinated compounds in human thyroid specimens, we have reevaluated a nonincineration technique which has so far been employed in the determination of thyroxine-iodine in peripheral blood.

The catalytic action of iodoamino acids in the Ce-As reaction was enhanced by a small amount of $\mathrm{Cl}_{2}$. On the contrary, a large amount of $\mathrm{Cl}_{2}$ inhibited the reaction unexpectedly. Among iodide, iodotyrosine and iodothyronine, iodide was the most effective catalyst in the Ce-As reaction and iodothyronine was the least effective one. Protein seemed to inhibit this reaction of thyroglobulin. But the result of iodine content in thyroglobulin by this technique agreed well with that by incineration when measured ${ }^{127} \mathrm{I}$ wascorrected by percent activity of dializable part of the total activity of ${ }^{131} \mathrm{I}$-thyroglobulin with the same protein concentration, after the $\mathrm{NaClO}$ treatment.

The results of human thyroid specimens were as follows: the thyroglobulin content of five normal subjects was $8.0 \pm 1.5 \%$ of wet thyroid weight. That of Hashimoto's disease was significantly decreased which seemed compatible with the decrease in iodine content of thyroglobulin, whereas thyroglobulin content of Graves disease treated with 1-methyl, 2-mercaptoimidazole followed by a large dose of iodide was well preserved in spite of a lower degree of iodination of thyroglobulin. As for the distribution of iodoamino acids-iodine in normal thyroid, $\mathrm{T}_{4}$ was $20.5 \pm 0.7 \%$.

This technique ultimately looks promising as a tool with which to study intrathyroidal iodine metabolism in human.
\end{abstract}

The intrathyroidal iodine metabolism in human has been mainly studied so far on newly iodinated compounds using radioactive iodine. But also the study of iodine metabolism in equilibrium, in other words, study of ${ }^{127}$ I metabolism should be essential in the whole aspect of metabolism.

It was, however, uncommon that the

\footnotetext{
Received April 8, 1977.

* Present address; Department of Pharmacology, The University of Texas, Health Science Center at Dallas, 5323 Harry Hines Blvd., Dallas, Texas, U.S.A.

** To whom reprint requests should be addressed.
}

papers concerned with ${ }^{127} \mathrm{I}$ metabolism in human were written. This seems to be due to complicated methods of analysis rather than to little opportunity of obtaining. specimens.

The nonincineration technique for thyroxine- $\left(\mathrm{T}_{4}\right)$-iodine by Pillegi and Kessler (1968). simplified the procedure by avoiding ashing. We intended to extend this simple technique for the determination of other iodinated compounds, monoiodotyrosine(MIT), diiodotyrosine(DIT), triiodothyronine $\left(\mathrm{T}_{3}\right)$ and thyroglobulin $(\mathrm{Tg})$.

The present study is mainly concerned 
with the basic one of this method and the clinical application to normal subjects, Hashimoto's disease and Graves disease.

\section{Materials and Methods}

\section{$0.1 \mathrm{~N}$ arsenious acid reagent}

With the aid of heat, $4.95 \mathrm{~g}$ of $\mathrm{As}_{2} \mathrm{O}_{3}$ (E. Merck A.G.) was dissolved in $25 \mathrm{ml}$ of $4 \% \mathrm{NaOH}$. This was added to $300 \mathrm{ml}$ of distilled water and then slightly acidified with approximately $4 \mathrm{ml}$ of $7 \mathrm{~N}$ $\mathrm{H}_{2} \mathrm{SO}_{4}$. This acidified solution was finally brought to $1,000 \mathrm{ml}$ with distilled water.

\section{$0.02 N$ ceric reagent}

$12.65 \mathrm{~g}$ of ceric ammonium sulfate, dihydrate $(\mathrm{G}$. Frederick Smith Chemical Co.) was dissolved in $500 \mathrm{~m} l$ of distilled water. This was added to $230 \mathrm{ml}$ of $7 \mathrm{~N} \mathrm{H}_{2} \mathrm{SO}_{4}$ and brought to $1,000 \mathrm{~m} l$ with distilled water.

\section{$0.01 \mathrm{~N} \mathrm{NaClO}$}

Sodium hypochlorite solution of estimated concentration $2.8 \mathrm{M}$ (Wako Pure Chemical Co.) was diluted 280 times with distilled water.

\section{Iodoamino acids and iodide standards}

Stock solutions of MIT, DIT, $\mathrm{T}_{3}, \mathrm{~T}_{4}$ and $\mathrm{KI}$; $10 \mathrm{mg}$ equivalent compounds in terms of iodide were dissolved in each $100 \mathrm{~m} l$ of distilled water with weak alkaline. Working standards were prepared freshly once a month, by diluting stock solutions 50 times with ethanol. A working standard of KI for measuring iodine content of $\mathrm{Tg}$ was prepared to contain $1 \mu \mathrm{g}$ of iodide per milliliter by diluting the stock with distilled water.

\section{Human thyroid tissue}

Thyroid tissues were obtained by surgery or autopsy.

\section{Labeled rat thyroid}

One Sprague-Dawley male rat fed on iodine sufficient diet (Oriental MF pellet) was injected with $500 \mu \mathrm{Ci}$ of carrier-free ${ }^{131} \mathrm{I}$ ip. One day after the injection the thyroid gland was taken out of the injected rat after killed by ether.

\section{Homogenization of human thyroid tissue}

$200-300 \mathrm{mg}$ of chopped thyroid tissue was suspended in $4 \mathrm{ml}$ of cold saline $0.01 \mathrm{M}$ phosphate buffer (pH 6.8). Homogenization was performed in a conial, glass motor-driven tissue grinder of $5 \mathrm{ml}$ capacity in cold. After removing cell debris by centrifugation at $2,000 \mathrm{rpm}$ for $10 \mathrm{~min}$, the supernatant was centrifuged at $105,000 \times \mathrm{g}$ for $60 \mathrm{~min}$. A portion of the clear supernatant was ajusted to contain $0.9 \%$ sodium chloride and $0.3 \mathrm{mM}$ Tris- $\mathrm{HCl}(\mathrm{pH} 8.5)$, and $0.05 \mathrm{M}$ 1-methyl, 2-mercaptoimidazole for the hydrolysis. The other portion was used for the study by sucrose density gradient ultracentrifugation.

Homogenization of labeled rat thyroid gland Procedures employed for homogenization, centrifugation and $\mathrm{pH}$ adjustment were the same as those for human thyroid specimens.

\section{Pronase hydrolysis}

Various amounts of human thyroid homogenate in relation to estimated iodine content were put into Thumberg tube and added to approximately 150,000 cpm of ${ }^{131} \mathrm{I}$-labeled rat thyroid homogenate which had apparently no effect to the chemical analysis of iodine and then added to 0.1 vol. of $5 \%$ pronase (Kaken Chemical Co.) solution. Anaerobic hydrolysis was undertaken at $37^{\circ} \mathrm{C}$ for $16 \mathrm{hr}$ (Inoue and Taurog, 1968). When the concentration of iodine in a sample was not enough for measurement, such a sample was concentrated after digestion under negative pressure with $\mathrm{N}_{2}$ gas charging so as to contain at least $0.6 \mu \mathrm{g}$ of the total iodine in $80 \mu l$ of hydrolysate. As a control, the same volume of saline $0.01 \mathrm{M}$ phosphate buffer instead of human homogenate was dealt with in the same way as a thyroid sample.

\section{Chromatography}

At the end of the digestion period, $50-80 \mu l$ of each digestion mixture corresponding to $0.6-0.8 \mu \mathrm{g}$ of iodine was delivered on a paper strip of Whatman $3 \mathrm{MM}$ for ascending chromatography with n-butanol-ethanol$0.5 \mathrm{~N} \mathrm{NH}_{4} \mathrm{OH}(5: 1: 2)$ solvent for $14 \mathrm{hr}$.

\section{Cutting and counting}

The paper strip was then exposed to X-ray film for $24 \mathrm{hr}$ in order to determine the location of iodide compounds and cut into fractions according to radioautogram. The radioactivity of each fraction was counted in a well-type scintillation counter (Aloka) before and after extraction.

\section{Extraction from paper}

Paper fractions were cut into small fragments and extracted in glass stoppered extraction tubes of $30 \mathrm{ml}$ capacity with $12 \mathrm{ml}$ of $50 \%$ acetic acid, $4 \mathrm{ml}$ of $2 \mathrm{~N}$ $\mathrm{HCl}$ and $4 \mathrm{ml}$ of $0.01 \mathrm{~N} \mathrm{NaClO}$ at $37^{\circ} \mathrm{C}$ for $30 \mathrm{~min}$. Radioactivity of an aliquot of each fraction was counted, as mentioned above, to determine extraction efficiency, which was used for a correction of measured ${ }^{127} \mathrm{I}$ data. 
Sucrose density gradient ultracentrifugation

Sucrose density gradient was made in a nitrocellurose tube of $5 \mathrm{ml}$ capacity with each $2.3 \mathrm{ml}$ of $20 \%$ sucrose in saline $0.01 \mathrm{M}$ phosphate buffer ( $\mathrm{pH}$ 6.8) and $5 \%$ one. A portion of the clear supernatant of the human thyroid sample $(0.3 \mathrm{~m} l$ containing less than $2.0 \mathrm{mg}$ of protein) with $100-200 \times 10^{3} \mathrm{cpm}$ of the clear supernatant of labeled rat thyroid homogenate was applied on the top of the sucrose density gradient. Three tubes were centrifuged simultaneously in a Hitachi swinging rotor (Model-40RPS) at $25,000 \mathrm{rpm}$ for $13 \mathrm{hr}$. After centrifugation, the bottom of the tube was punctured and consecutive fractions were collected, each consisting of 10 drops. After radioactivities of samples had been counted, the same fractions were then used for the protein measurement (Lowry et al., 1951).

\section{Purification of $\mathrm{T} g$}

The samples of each three fractions of main protein peak around $19 \mathrm{~S}$ were collected into Visking tube and dialized against $2,000 \mathrm{~m} l$ of cold saline for $12 \mathrm{hr}$ twice. Otherwise, the clear supernatant was purified by ammonium sulfate fractination (Ui and Tarutani, 1961). The supernatant of $1.55 \mathrm{M}$ ammonium sulfate was dialized against $1,000 \mathrm{~m} l$ of cold saline for $6 \mathrm{hr}$ three times.

\section{Iodine determination}

Each $5-\mathrm{m} l$ extract was transferred into a test tube of $12 \mathrm{ml}$ capacity, containing $0.5 \mathrm{ml}$ of arsenious acid reagent, and then these were well mixed. Finally $1 \mathrm{ml}$ of ceric reagent was added to the mixture and the mixture was incubated at $25^{\circ} \mathrm{C}$ for $20 \mathrm{~min}$. At the end of incubation, the reaction was stopped by adding 2 drops of $0.2 \mathrm{~N} \mathrm{HgNO}_{3}$. Samples for a standard curve were added with $3 \mathrm{ml}$ of $50 \%$ acetic acid, $1 \mathrm{~m} l$ of $2 \mathrm{~N} \mathrm{HCl}$ and $1 \mathrm{~m} l$ of $0.01 \mathrm{~N} \mathrm{NaClO}$, and then this was dealt with in the same way as extract. Per cent transmittance (T\%) of sample was read at $420 \mathrm{~nm}$ under the light path of $0.1 \mathrm{~mm}$.

\section{$T g$ content}

This was calculated from the following factors, wet tissue weight, protein concentration of the clear supernatant and per cent of $\mathrm{Tg}$ of thyroid soluble protein.

\section{Results}

\section{Incubation temperature and time}

Various amounts of iodide in a volume of $1 \mathrm{~m} l$ were added to a tube containing $3 \mathrm{~m} l$ of $50 \%$ acetic acid, $1 \mathrm{~m} l$ of $2 \mathrm{~N} \mathrm{HCl}$, $1 \mathrm{~m} l$ of $0.01 \mathrm{~N} \mathrm{NaClO}, 0.5 \mathrm{~m} l$ of $0.1 \mathrm{~N}$. As reagent and $1 \mathrm{~m} l$ ceric ammonium.

As shown in Fig. 1, the catalytic action of iodide with the reduction of ceric ammonium was accelerated in proportion to incubation temperature.

As we could obtain enough sensitivity at $25^{\circ} \mathrm{C}$ which was almost equal to room temperature, we conducted all experiments at this temperature for $20 \mathrm{~min}$.

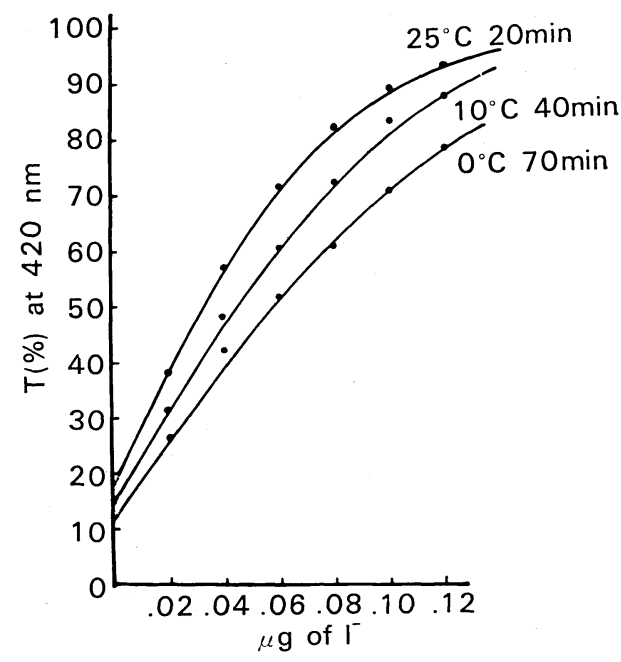

Fig. 1. Incubation temperature and time. The catalytic action of iodide was accelerated in proportion to incubation temperature.

\section{The effect of DIT on the catalytic reaction}

In order to test if the other iodoamino acids than $\mathrm{T}_{4}$ could catalize As-Ce reaction in this system, we examined the effect of DIT. As shown in Fig. 2, DIT catalized the reduction of ceric ammonium by itself in an acid solution, furthermore the catalytic action of DIT was apparently enhanced by adding a small amount of $\mathrm{NaClO}$.

This enhancement seemed to be owing to a small amount of $\mathrm{Cl}_{2}$ produced by $\mathrm{HCl}$ and $\mathrm{NaClO}$ (Pileggi and Kessler, 1968).

The effect of various concentrations of $\mathrm{NaClO}$ on the catalytic action of DIT

As shown in Fig. 3 where the molar concentration of $\mathrm{NaClO}$ was expressed in 


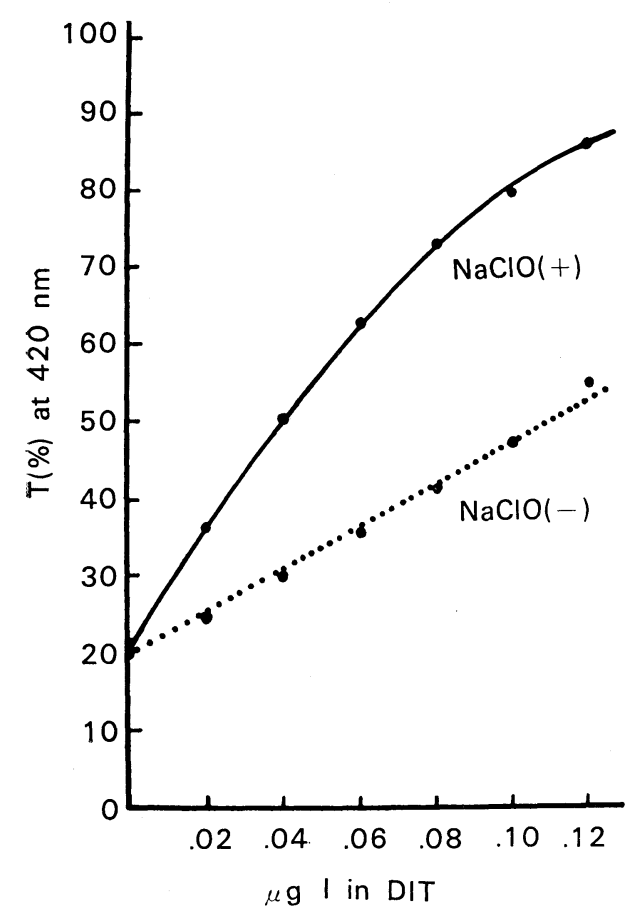

Fig. 2. DIT measured by the nonincineration technique (solid line) in contrast to the control (broken line). Catalytic action of DIT was apparently enhanced by adding $\mathrm{NaClO}$. This was supposed to be owing to $\mathrm{Cl}_{2}$ produced by $\mathrm{HCl}$ and $\mathrm{NaClO}$.

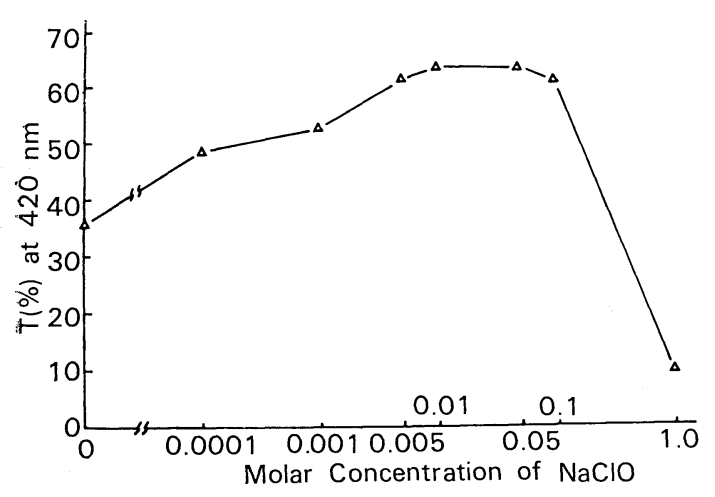

Fig. 3. Evaluation of $\mathrm{Cl}_{2}$ for this assay. Concentration of $\mathrm{NaClO}$ was expressed in molar concentration of $\mathrm{NaClO}$ solution. Relatively low concentration of $\mathrm{Cl}_{2}$ looks favorable for this assay. molar concentration of the reagents, the plateau of enhancement was observed between $0.01 \mathrm{~m}$ and $0.05 \mathrm{M}$. On the other hand, $\mathrm{T}(\%)$ at $1.0 \mathrm{M}$ was rather lower than that at zero point, suggesting that the reaction was apparently inhibited by an excessive amount of $\mathrm{Cl}_{2}$. Ultimately $0.01 \mathrm{~m}$ $\mathrm{NaClO}$ was employed for all experiments.

The determination of iodoamino acids

Equivalent iodomino acids in terms of iodide content were determined by the nonincineration technique. As shown in Fig. 4, there was practically no difference between MIT and DIT, and also it was the same with $\mathrm{T}_{3}$ and $\mathrm{T}_{4}$.

$\mathrm{T}(\%)$ of iodotyrosine was higher than that of iodotyronine in the same iodine basis, indicating that iodotyrosine was more an effective catalyst in this reaction than iodothyronine. As shown in Fig. 5, T(\%) of iodide was the highest among these three

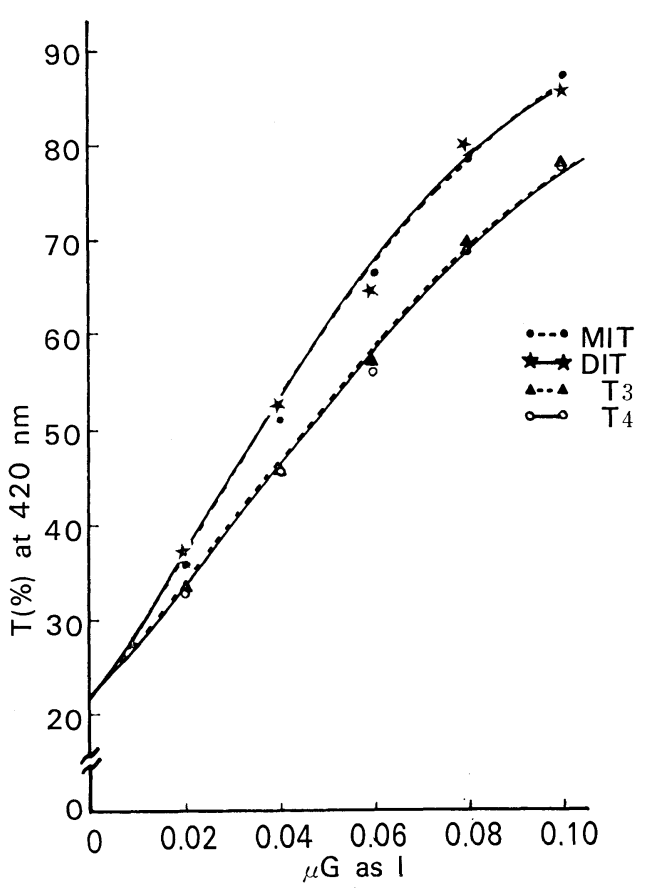

Fig. 4. Determination of iodoamino acids. $\mathbf{T}(\%)$ of iodotyrosine was higher than that of iodothyroine. 


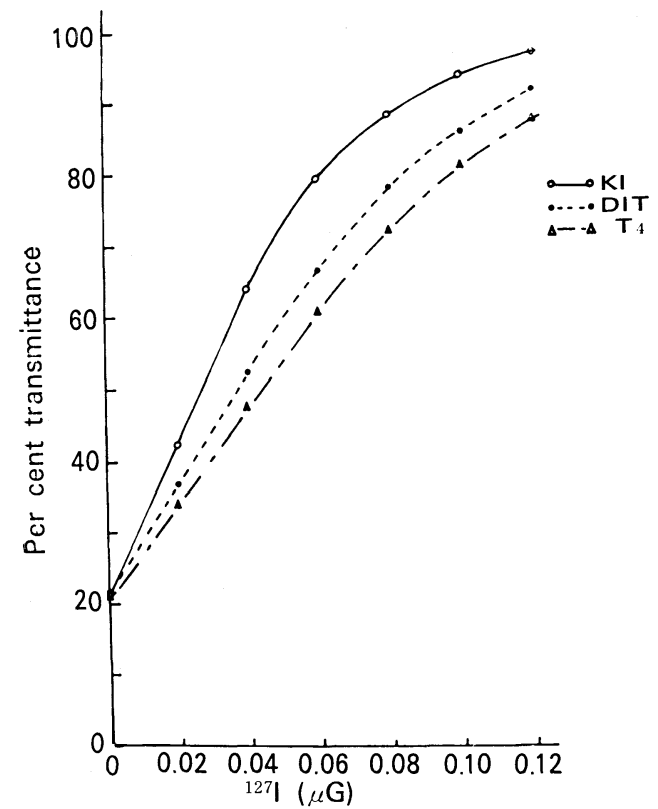

Fig. 5. Determination of iodide and iodoamino acids. $\mathrm{T}(\%)$ of iodide was the highest.

kinds of compounds, indicating that iodide was the most effective catalyst.

\section{Extraction from paper}

Iodide and iodoamino acids were extracted from paper fragments in a mixture of $6 \mathrm{~m} l$ of $50 \%$ acetic acid, $2 \mathrm{ml}$ of $2 \mathrm{~N}$ $\mathrm{HCl}$ and $2 \mathrm{~m} l$ of $0.01 \mathrm{~N} \mathrm{NaClO}$. Extraction efficiencies were calculated from ${ }^{131} \mathrm{I}$ activities before and after the extraction. Iodide and iodoamino acids on paper were sufficiently extracted almost 100\%.

\section{Recovery of iodide}

Experiments were conducted with each $0.50 \mu \mathrm{g}$ of iodide. Chemical purity of ${ }^{127} \mathrm{I}$ was $94.9 \pm 1.3 \%$ by paper chromatography. Determined ${ }^{127} \mathrm{I}$ expressed in per cent of expected ${ }^{127} \mathrm{I}$ on paper fragment was $99.0 \pm$ $1.1 \%$, suggesting that there was practically no interfering substance of the reaction in extracts. The final recovery of ${ }^{127} \mathrm{I}$ was $93.9 \pm 1.0 \%$.
Iodide determination of $\mathrm{Tg}$

Iodide content of $\mathrm{Tg}$ was determined in the same way as iodoamino acids or iodide. As shown in the top of Fig. 6, measured ${ }^{127} \mathrm{I}$ of purified $\mathrm{Tg}$ was lower than expected ${ }^{127}$ I which was previously determined by the incineration method (Barker, 1964). It was assumed that protein might inhibit the reaction. In fact, bovine serum albumin (BSA) inhibited iodide determination of $\mathrm{Tg}$. Iodide determination of $13.2 \mu \mathrm{g}$ of $\mathrm{Tg}$ was inhibited $7 \%, 9 \%$ and $15 \%$ by adding
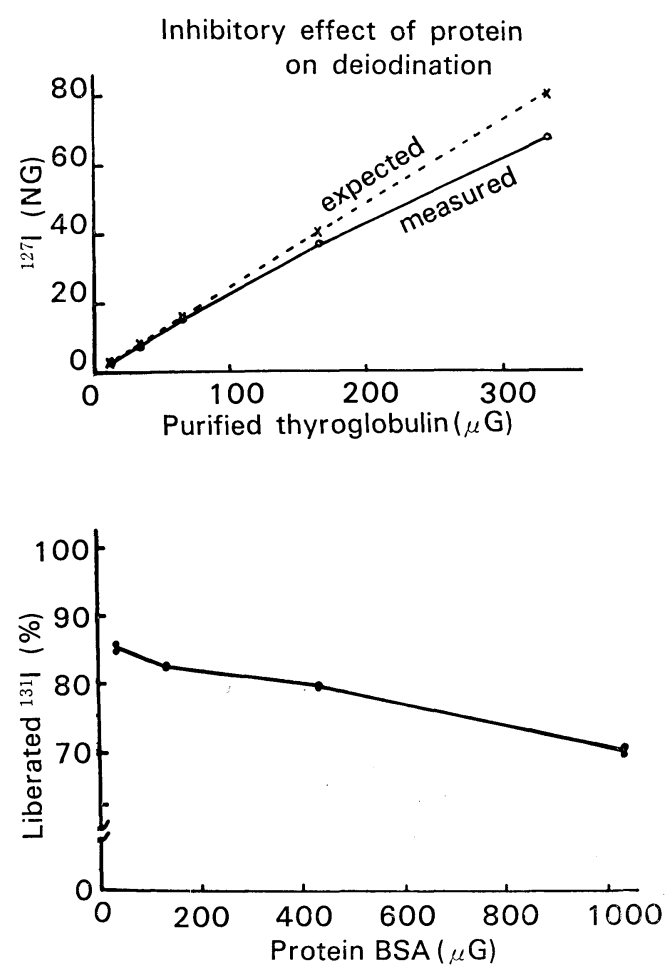

Fig. 6. Top of the Fig. shows iodine determination of a human $\mathrm{Tg}$ purified by sucrose density gradient ultracentrifuge. Measured ${ }^{127} \mathrm{I}$ was lower than expected ${ }^{127} \mathrm{I}$. Various amounts of BSA were added to ${ }^{131} \mathrm{I}$-labeled rat $\mathrm{Tg}$ purified by sucrose density gradient ultracentrifuge. These were dealt with an acid mixture of $50 \%$ acetic acid, $2 \mathrm{~N} \mathrm{HCl}$ and $0.01 \mathrm{~N} \mathrm{NaClO}$ and then dialized against saline. ASA inhibited a conversion of ${ }^{131} \mathrm{I}-\mathrm{Tg}$ into a dializable form shown in the bottom. 
$50 \mu \mathrm{g}, 100 \mu \mathrm{g}$ and $150 \mu \mathrm{g}$ of $\mathrm{BSA}$, respectively. When ${ }^{131} \mathrm{I}$ labeled $\mathrm{Tg}$ was dealt with a mixture of $50 \%$ acetic acid, $2 \mathrm{~N}$ $\mathrm{HCl}$ and $0.01 \mathrm{~N} \mathrm{NaClO}$ and then the mixture was dialized against saline, most radioactivity was found in the sample outside of dialysis bag. But this conversion of ${ }^{131} \mathrm{I}-\mathrm{Tg}$ into some dializable form in the presence of an acid mixture was alsoi nhibited by adding various amounts of BSA into the mixture, shown in Fig. 6, bottom. In addition, the degree of this inhibition by BSA was almost equal to that of inhibi-tion of iodide determination of $\mathrm{Tg}$ by BSA. Therefore, iodine in $\mathrm{Tg}$ is probably changed by an acid mixture, into some dializable form; iodide, iodoamino acids and small peptide including iodide to catalize As-Ce reaction.

As was mentioned above, protein seemed to inhibit the iodide determination of $\mathrm{Tg}$. However, after correcting nonincineration's data by the percent activity of dializable part of the total activity of standard ${ }^{131} \mathrm{I}-\mathrm{Tg}$ with same protein amount under the $\mathrm{NaClO}$ treatment, in other words, correcting the data by the inhibiting factor relating to protein amount, the results of iodine content of $\mathrm{Tg}$ by the nonincineration technique agreed well with those by Barker's incineration method.

Intrathyroidal distribution of iodine compound in normal and patients' thyroid

As shown in Table $1, \mathrm{Tg}$ content of euthyroid subjects was $8.0 \pm 1.5 \%$ of wet thyroid weight. That of Hashimoto's disease patients was decreased. But that of Graves disease patients treated with 1-methyl, 2mercaptoimidazole and a large dose of iodide was not significantly decreased. The degree of iodination of $\mathrm{Tg}$ from euthyroid subjects was $0.49 \pm 0.03 \%$. Tg from Hashimoto's disease patients and treated Graves disease patients were poorly iodinated.

Table 1. Intrathyroidal distributions of iodoamino acids-iodine in normal subjects, treated Graves disease patients and Hashimoto's disease patients.

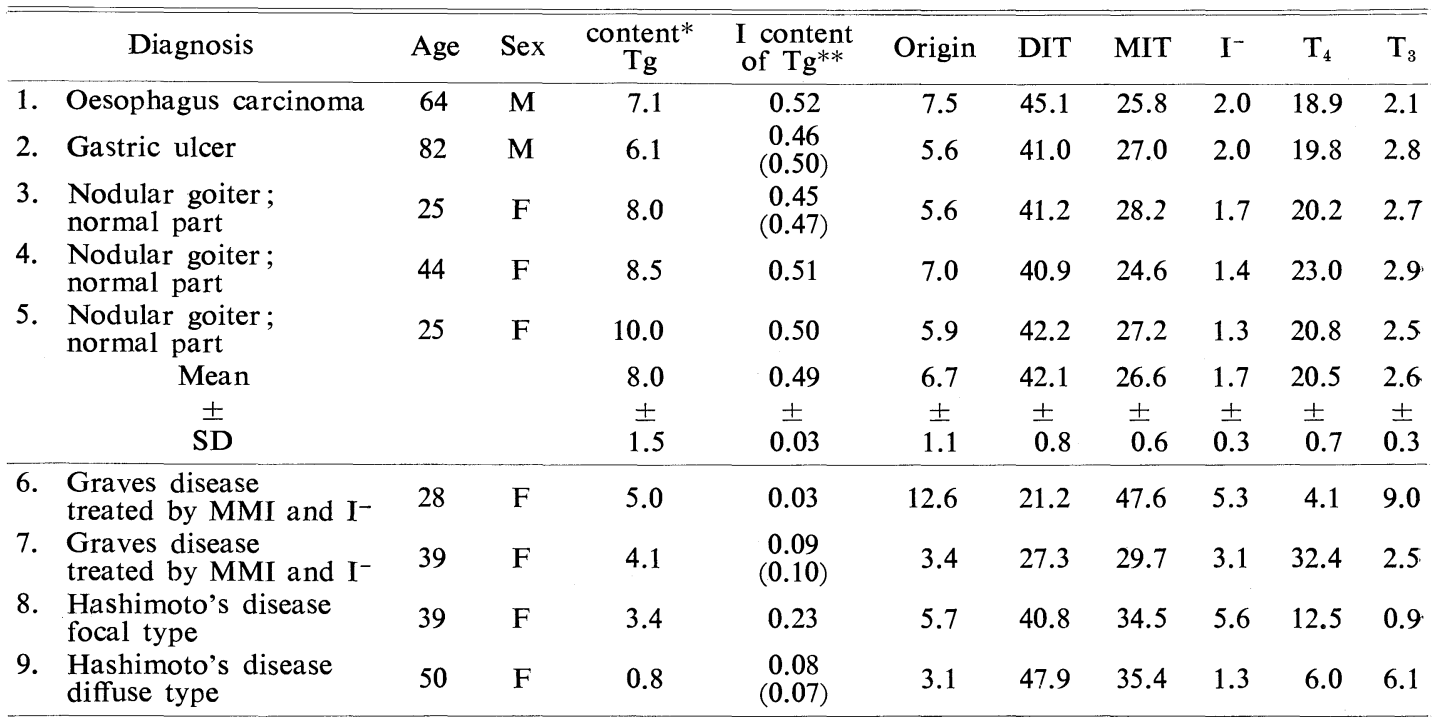

* Purified $\mathrm{Tg}$ and thyroid homogenate were used for iodine content of $\mathrm{Tg}$ and the other iodine compounds, respectively. $\mathrm{Tg}$ content was expressed in per cent of wet thyroid weight and other data were also expressed in per cent.

** Results of $\mathrm{I}$ content of $\mathrm{Tg}$ in paretheses were obtained with samples prepared by ammonium sulfatefractionation. 
The ratios of iodoamino acids in euthyroid subjects were as follows: $0.63 \pm 0.5$ for MIT/DIT, $0.49 \pm 0.05$ for $\mathrm{T}_{4} / \mathrm{DIT}$ and 0.13 \pm 0.01 for $T_{3} / T_{4}$. And $T_{4}$-iodine was 20.5 $\pm 0.7 \%$ of total iodine in the thyroids from euthyroid subjects.

On the other hand, the total iodothyronines were decreased in most patients with poorly iodinated $\mathrm{Tg}$.

\section{Discussion}

Simplicity of the nonicineration technique for the chemical determination of $\mathrm{T}_{4}$ is more than a match for the alkaline-ashing method. It is quite natural that we should try to apply this technique for only $\mathrm{T}_{4}$-iodine to the determination of the other iodinated compounds of the thyroid.

In fact, we observed that DIT also catalized the reduction of ceric ammonium in the presence of $\mathrm{NaClO}$. Although DIT catalized the reaction in an acid solution by itself, its catalizing ability was apparently enhanced by the $\mathrm{NaClO}$ treatment.

When equivalent potassium iodide and iodoamino acids in terms of iodide amount were determined, there was no difference between the values from MIT and DIT, and it was the same with $\mathrm{T}_{3}$ and $\mathrm{T}_{4} . \quad \mathrm{T}(\%)$ value of iodothyronine was, however, lower than that of iodotyrosine. And $\mathrm{T}(\%)$ of iodoamino acids was lower than that of inorganic iodide. These results suggest that tyrosine and thyronine might suppress the reaction of those iodinated compounds in this assay system. Practically, it is necessary for us to prepare the standard curves of these three kinds of iodine compounds, that is inorganic iodide, iodotyrosine and iodothyronine when we actually determine samples.

As was above mentioned, the $\mathrm{NaClO}$ treatment enhanced the catalytic activity of DIT. This seemed to depend on iodide oxidatively released from tyrosine by the action of $\mathrm{Cl}_{2}$ since it had been decribed by Pileggi and Kessler (1968). In our experiment by paper chromatography, however, iodide fraction was not so much increased after the $\mathrm{NaClO}$ treatment of iodoamino acids or $\mathrm{Tg}$. The reason for this was not known. But it was reported that the catalytic activity of $T_{4}$ in the ceric arsenite reaction resulted from the release of iodide from $T_{4}$ molecule by the action of ceric ion (Bowden et al., 1955). At this point, the $\mathrm{NaClO}$ treatment might readily make iodoamino acids susceptible to release much iodide by ceric ion.

As for the extraction method, Mandl and Block described a high yield of iodine, about $98 \%$ when iodo compounds in a proteolytic digest of iodo proteins were extracted by n-butanol (Mandl and Block, 1959). Also, in the present experiment, extraction efficiencies of iodoamino acids from papers were almost $100 \%$, indicating that correction of measured ${ }^{127}$ I by extraction efficiency was practically unnecessary. However, extraction efficiency fluctuated to a very small extent in assays. Subsequently, if one would like to have very precise data, it is necessary to correct the results with extraction efficiencies.

In determination of $\mathrm{Tg}$-iodine, measured ${ }^{127} \mathrm{I}$ was lower than expected one. This was presumed to be an inhibition by protein. In order to study this question, the effect of BSA on the determination of Tg-iodine was examined. And BSA actually inhibited the determination of Tg-iodine. Therefore, we should take account for the inhibitory action of protein in this assay. Supposedly tyrosine and/or thyronine might suppress the reaction. But it is considered that there is practically no problem, because the results by this technique agreed well with those by incineration if measured ${ }^{127} \mathbf{I}$ was corrected by the percent activity of dializable part of ${ }^{131} \mathrm{I}-\mathrm{Tg}$ with the same protein concentration after the $\mathrm{NaClO}$ treatment. Also it would be a good way 
Table 2. Per cent distribution of iodoamino acids-iodine in normal subjects.

\begin{tabular}{lccccccccc}
\hline & & $\mathrm{I}^{-}$ & $\mathrm{DIT}$ & $\mathrm{MIT}$ & $\mathrm{T}_{4}$ & $\mathrm{~T}_{3}$ & $\mathrm{MIT} / \mathrm{DIT}$ & $\mathrm{T}_{4} / \mathrm{DIT}$ & $\mathrm{T}_{3} / \mathrm{T}_{4}$ \\
\hline Arosenius (1964) & 6 & $*$ & 35 & 33 & 24 & 8 & 0.88 & 0.69 & 0.34 \\
Braasch et al $(1955)$ & 5 & 6 & 25 & 17 & 35 & 8 & 0.68 & 1.40 & 0.23 \\
Dimitriadou et al $(1966)$ & 5 & $*$ & 41 & 38 & -22 & & 0.93 & - & - \\
Ermans et al (168) & 7 & 10 & 33 & 33 & 16 & 8 & 1.00 & 0.48 & 0.50 \\
Rolland et al (1970) & $?$ & $6^{* *}$ & 27 & 49 & 16 & 5 & 1.83 & 0.59 & 0.18 \\
& & $(0.26)$ & $(1.9)$ & $(4.9)$ & $(1.0)$ & $(0.2)$ & & & \\
Present data & 5 & 2 & 42 & 27 & 21 & 3 & 0.64 & 0.50 & 0.14 \\
\hline
\end{tabular}

* Not written in the papers.

** These were calculated from values expressed in mole in parentheses.

to determine $\mathrm{Tg}$-iodine in samples with a fixed amount of protein.

As shown in Table 2, the present data with intrathyroidal distribution of iodoamino acids-iodine of normal subjects are significantly different from those of other authors except $\mathrm{T}_{4}$ (Arosenius, 1964; Braasch et al., 1955; Dimitriadou et al., 1966; Ermans et al., 1968; Rolland et al., 1970). MIT/DIT and $T_{3} / T_{4}$ ratios of our data are significantly lower than those by the other authors. There seems to be a difficult problem to compare our data with those from other countries because people in Japan take sea weed frequently, which is known to be rich in iodine. Nagataki et al. (1972) also reported low $T_{3} / T_{4}$ ratio in normal Japanese.

Consequently higher ratios of MIT/DIT and $T_{3} / T_{4}$ of the other authors might suggest the relatively iodine deficient state in those countries. On the other hand, $\mathrm{T}_{4} / \mathrm{DIT}$ of ours was almost the same to the others' data.

As for inorganic iodide fraction, we recognized significantly lower values comparing to others' data in spite of the determination after digestion. This seems to be owing to the anaerobic technique of hydrolysis described by Inoue and Taurog (Inoue and Taurog, 1968).

Decrease in $\mathrm{Tg}$ content of the thyroid of Hashimoto's disease seems to be compatible with decrease in iodine content of Tg. Tg content of the thyroid of treated
Graves disease, however, was well preserved in spite of low iodine content of Tg. This might be owing to a large dose of exogenous iodide which supposedly inhibit proteolysis of $\mathrm{Tg}$.

In most patients with poorly iodinated $\mathrm{Tg}$, decreases in the total iodothyronines and much higher ratios of $T_{3} / T_{4}$ were observed. One case of Graves showed, however, a rather higher value of $T_{4}$ in spite of a low degree of iodination of $\mathrm{Tg}$ with higher MIT/DIT. This case took a long term and a large dose of 1-methyl, 2-mercaptoimidazole to obtain the euthyroid state, whereas another case of Graves disease with lower $\mathrm{T}_{4}$ had rather become hypothyroidism medicamentosa in a short period. It seems that at least some case of Graves disease might have a strong ability of $\mathrm{T}_{4}$ formation. This technique ultimately looks promising as a tool with which to study intrathyroidal iodine metabolism in human.

\section{Acknowledgement}

We are greatly indebted to Prof. K. Tanaka of the Department of Pathology, Kyushu University for his kind supply of thyroid glands. We are also indebted to Prof. A. Taurog of Southwestern Medical School, the University of Texas for his helpful discussions to prepare the manuscript. 


\section{References}

Arosenius, K. E. (1964). Scand. J. Clin. Lab. Invest. 16, 440.

Barker, S. B. (1964). Biochem. J. 90, 214.

Bowden, C. H., N. F. Maclagan and J. H. Wilkinson (1955). ibid. 59, 93.

Braasch, J. W., A. Albert, F. R. Keating and B. M. Black (1955). J. Clin, Endocr. Metab. 15, 732.

Dimitriadou, A., R. Suwanik, T. R. Fraser and J. D. Pearson (1966). J. Endocr. 34, 23.

Ermans, A. M., J. Kinthaert, C. Delcroix and J. Collard (1968). J. Clin. Endocr. Metab. 28, 169.
Inoue, K. and A. Taurog (1968). Endocrinology 83, 816.

Lowry, O. H., N. J. Rosebrough, A. L. Farr and R. J. Randall (1951). J. Biol. Chem. 193, 265.

Mandl, R. H. and R. J. Block (1959). Arch Biochem. Biophys. 81, 25.

Nagataki, S., H. Uchimura, Y. Matsuyama, K. Nakao and K. Ito (1972). J. Clin. Endocr. Metab. 35, 18.

Pileggi, V. J. and G. Kessler (1968). Clin. Chem. 14, 339.

Rolland, M., R. Aquaron and S. Lissitzky (1970). Analyt. Biochem. 33, 307.

Ui, N. and O. Tarutani (1961). J. Biochem. 50, 508. 